\title{
Functions of $S$-nitrosylation in plant hormone networks
}

\section{Ramiro París, María J. Iglesias, María C. Terrile and Claudia A. Casalongué*}

Instituto de Investigaciones Biológicas, Facultad de Ciencias Exactas y Naturales, Unidade Ejecutora-Consejo Nacional de Investigaciones Científicas y Técnicas - Universidad Nacional de Mar del Plata, Mar del Plata, Argentina

\section{Edited by:}

Emmanuel Baudouin, Université

Pierre et Marie Curie - Paris 6, France

\section{Reviewed by:}

Georgia Tanou, Aristotle University of Thessaloniki, Greece

Christian Lindermayr, Helmholtz

Zentrum München - German

Research Center for Environmental

Health, Germany

\section{${ }^{*}$ Correspondence:}

Claudia A. Casalongué, Instituto de Investigaciones Biológicas, Facultad de Ciencias Exactas y Naturales, Unidade Ejecutora-Consejo Nacional de Investigaciones Científicas y Técnicas - Universidad Nacional de

Mar del Plata, Funes 3250, CC 1245,

7600 Mar del Plata, Argentina

e-mail: casalong@mdp.edu.ar
In plants, a wide frame of physiological processes are regulated in liaison by both, nitric oxide (NO) and hormones. Such overlapping roles raise the question of how the cross-talk between $\mathrm{NO}$ and hormones trigger common physiological responses. In general, NO has been largely accepted as a signaling molecule that works in different processes. Among the most relevant ways $\mathrm{NO}$ and the NO-derived reactive species can accomplish their biological functions it is worthy to mention post-translational protein modifications. In the last years, $S$-nitrosylation has been the most studied NO-dependent regulatory mechanism. Briefly, $S$-nitrosylation is a redox-based mechanism for cysteine residue modification and is being recognized as a ubiquitous regulatory reaction comparable to phosphorylation. Therefore, it is emerging as a crucial mechanism for the transduction of NO bioactivity in plants and animals. In this mini-review, we provide an overview on $S$-nitrosylation of target proteins related to hormone networks in plants.

Keywords: nitric oxide, phytohormones, redox mechanism, signaling, $S$-nitrosylation

\section{INTRODUCTION}

Nitric oxide (NO) is a free-radical product of cell metabolism, being nitrate reductase the best characterized enzymatic pathway for NO production in plants. However, other reductive and oxidative routes have been also described (Lamattina and Polacco, 2007). It functions as a ubiquitous signal involved in diverse physiological processes and it is frequently implicated in multiple cell signaling events under the control of phytohormones including growth, development, and stress responses. Nevertheless, in most cases the molecular mechanisms underlying NO action in the plant cell are still undeciphered. The overlapping roles between plant hormones and NO raise the question of how both molecules may act in coordination. In general, regulatory effects of $\mathrm{NO}$ are mediated through protein modifications, including tyrosine nitration, metal nitrosylation, and $S$-nitrosylation of cysteines. Thus, the identification of NO primary targets has provided new opportunities to link NO reactivity and biological processes. In this review, we highlight the progress brought by the identification of $S$-nitrosylated target proteins related to stress and growthpromoting plant hormones. Our focus is the broad role of this post-translational modification that allows $\mathrm{NO}$ to modulate plant hormone homeostasis as well as signaling pathways. However, the participation of NO beyond its action through $S$-nitrosylation in hormone-regulated processes is out of the scope of this work and it is widespreadly covered in recent reviews by Simontacchi et al. (2013) and Astier and Lindermayr (2012).

\section{$S$-NITROSYLATION AS AN EMERGING POST- TRANSLATIONAL MODIFICATION OF PLANT PROTEINS}

$S$-nitrosylation is the reversible binding of a NO moiety to a reactive cysteine residue of a target protein to form an $S$-nitrosothiol
(SNO; Stamler etal., 2001). It is recognized as a reversible and ubiquitous regulatory reaction. Thus, like in animals, this redox-based post-translational mechanism is also crucial for the transduction of NO bioactivity in many plant cellular responses (Hess et al., 2005). At first, protein S-nitrosylation was thought to be controlled mainly through the regulation of NO biosynthesis. However, in mammals it has been postulated as a short-range $\mathrm{NO}$ post-translational mechanism limited to proximity of NO sources (Martinez-Ruiz et al., 2013). In addition to the enzymatic NO-producing enzymes, it is important to consider that both, favorable environment to $S$-nitrosylating agent formation as well as transnitrosylating reactions could promote the expansion of the S-nitrosylation range of action (Martinez-Ruiz et al., 2013). The SNO turnover could also provide an alternative mechanism to control protein $S$-nitrosylation in the cell. Given the labile nature of this post-translational modification, it was conceived initially as a spontaneous and non-regulated process. However, different denitrosylase enzymes have been described, which directly mediate denitrosylation or govern the cellular equilibrium between protein and low-molecular weight SNOs. Two main enzymatic systems have emerged as physiologically relevant denitrosylases: the glutathione/S-nitrosoglutathione reductase (GSH/GSNOR) and the thioredoxin/thioredoxin reductase (Trx/TrxR; Benhar et al., 2009). $S$-nitrosylation of the major intracellular antioxidant tripeptide GSH forms $S$-nitrosoglutathione (GSNO) that functions as a mobile reservoir of NO. Consequently, the enzyme GSNOR or GSNOR1 in Arabidopsis does not display a direct denitrosylase activity but controls intracellular levels of both, GSNO and SNO affecting the global level of $S$-nitrosylation (Feechan et al., 2005; Malik et al., 2011). On the other side, the mechanism described in animals for Trx denitrosylation involves direct interaction 
with SNO-proteins by formation of an intermolecular disulphide intermediate in which Trx is covalently linked to the substrate protein through a disulphide bridge, or transnitrosylation in which Trx is transiently $S$-nitrosylated (Benhar et al., 2009). Trx have been also described in the denitrosylation process taking part in hormonal signaling in plants (Tada et al., 2008). Therefore, it appears that the balance between $S$-nitrosylation/denitrosylation is critical for the precise transduction of NO signal.

$S$-glutathionylation is the post-translational modification of protein cysteine residues by the addition of GSH (MartinezRuiz and Lamas, 2007). The integrative interplay between protein $S$-glutathionylation and $S$-nitrosylation could be recognized as another crucial network for post-translational modification of certain proteins. Although the $S$-glutathionylation of proteins has been generally described more than 20 years ago, the identification of protein targets for this modification remains rather unexplored. Interestingly, for some mammal proteins involved in clinical disorders such as cardiovascular disease and diabetes among others, $S$-nitrosylation has been described as an intermediate for more stable modifications like $S$-glutathionylation (Martinez-Ruiz and Lamas, 2007). In summary, $S$-nitrosylation is crucial for NO signal transduction pathway but it should also be noted that other related-S-nitrosylation regulators can converge in NO-mediated protein functionality in plants.

\section{$S$-NITROSYLATION OF TARGET PROTEINS LINKED TO STRESS PHYTOHORMONES}

Salicylic acid (SA) and ethylene (ET) are key signaling molecules for plants in the resistance to biotic stress (Fujita et al., 2006; Loake and Grant, 2007). NO has an essential role in restriction of pathogen attack by induction of the defense response and programed host cell death (reviewed by Mur et al., 2013). Thus, NO bioactivity may exert a role on SA and ET hormone signaling pathways.

In Arabidopsis, one of the first comprehensive proteomic studies allowed the identification of more than $100 \mathrm{~S}$-nitrosylated proteins (Lindermayr etal., 2005). Interestingly, one of the identified $S$-nitrosylated proteins corresponded to a methionine adenosyltransferase (MAT) which catalyzes the synthesis of $S$ adenosylmethionine (SAM), a substrate for ET biosynthesis. Later on, Lindermayr et al. (2006) provided the first detailed molecular characterization of an $S$-nitrosylated target protein in plants. This study describes the $S$-nitrosylation of Cys-114 residue of the MAT1 isoform and the consequently inhibition of its activity. The enzymes $S$-adenosylhomocysteinase and cobalamin-independent methionine synthase are also part of the methylmethionine cycle and both enzymes have been found to be $S$-nitrosylated in proteomic analysis in Arabidopsis and Kalanchoe pinnata plants (Lindermayr et al., 2005; Abat et al., 2008). Activation/inactivation of these enzymes controls the SAM pool impacting in ET biosynthesis. All these evidences point out a multi-step control of ET biosynthesis by $S$-nitrosylation and opened the possibility to elucidate new mechanisms of NO and ET cross-talk (Figure 1A).

Salicylic acid is synthesized by plants in response to pathogen infection and is essential to the establishment of resistance mechanisms, including host cell death and systemic acquired resistance.
Mutations in AtGSNOR1 showed a pivotal role in the GSNO turnover, influencing cellular SNO levels under both, basal conditions and attempted microbial attack (Feechan et al., 2005). Interestingly, in the absence of AtGSNOR1 both SA biosynthesis and signaling are affected, suggesting that $S$-nitrosylation may control at least, two nodes of the SA-signaling network. GSNOR1 regulates the $S$-nitrosylation extent of non-expresser of pathogenesis-related gene1 (NPR1) and SA binding protein 3 (SABP3; Tada et al., 2008; Wang et al., 2009). S-nitrosylation of SABP3 is triggered during bacterial infection and suppresses SA binding capacity and carbonic anhydrase (CA) activity (Wang et al., 2009). Since, CA activity is required for the establishment of plant disease resistance, its inhibition by $S$-nitrosylation during late infection stages could contribute to a negative feedback loop which could be crucial for the proper modulation of SA-dependent plant defense mechanism (Figure 1B).

$S$-nitrosylation also exerts a key redox control of systemic acquired resistance in plants through targeting NPR1/TGA1 system. The SA NPR1-dependent signaling mechanism is mediated by redox changes that lead to reduction of NPR1 cysteines. This event switches NPR1 from cytosolic, disulfide-bound oligomers, to active monomers that are subsequently translocated into the nucleus and interacts with the TGA class of basic leucine zipper transcription factors. The result is an enhanced binding activity of TGA1 to the promoter region of pathogenesis-related (PR) genes, stimulating SA-dependent immune defense (Vlot et al., 2009). Upon pathogen attack, SA induces Trx which facilitates NPR1 monomerization, nuclear translocation, and activation of PR genes (Tada et al., 2008). Additionally, Tada et al. (2008) demonstrated that NPR1 is an S-nitrosylated protein. Notably, TGA1 is regulated by $S$-nitrosylation and $S$-glutathionylation improving TGA1 binding activity to PR1 promoter region (Lindermayr et al., 2010). However, it has not been demonstrated which type of modification, $S$-nitrosylation, $S$-glutathionylation, and/or both, is responsible for such protein-DNA binding activity (Figure 1B).

Concluding, plant immunity is regulated by a precise redox balance between the opposing actions of distinct redox-signals that catalyze NPR1 oligomer-monomer switch and NPR1/TGA1 interaction through transient redox fluctuations that includes $S$ nitrosylation and $S$-glutathionylation. Moreover, in the cytosol NPR1 also contributes to the suppression of jasmonic acid (JA)-dependent responses (Spoel et al., 2003), evidencing Snitrosylation as a mediator of the integrative hormonal regulation network for guarantee immunity in plants.

Meanwhile, abscisic acid (ABA) is the major player mediating adaptation of plants to drought stress. ABA induces stomatal closure and inhibits stomatal opening by facilitating osmotic solute loss to reduce guard cell turgor. These events take place through a complex signaling network that involves multiple components including $\mathrm{Ca}^{2+}, \mathrm{K}^{+}, \mathrm{IP}_{3}, \mathrm{MAPK}$, and $\mathrm{H}_{2} \mathrm{O}_{2}$ (Fan et al., 2004). $\mathrm{NO}$ enhances plant tolerance to drought and it contributes to stomatal closure evoked by ABA. Mechanistically, NO regulates inwardrectifying $\mathrm{K}^{+}$channels through its action on $\mathrm{Ca}^{2+}$ release from intercellular stores. Alternative pathways have been also indicated for $\mathrm{NO}$ action on the outward-rectifying $\mathrm{K}^{+}$channels, which are $\mathrm{Ca}^{2+}$ insensitive. It is probable that NO directly modifies the $\mathrm{K}^{+}$ 
A

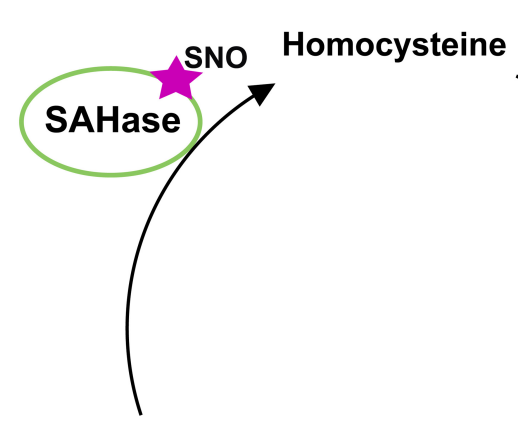

S-Adenosyl-L-homocysteine
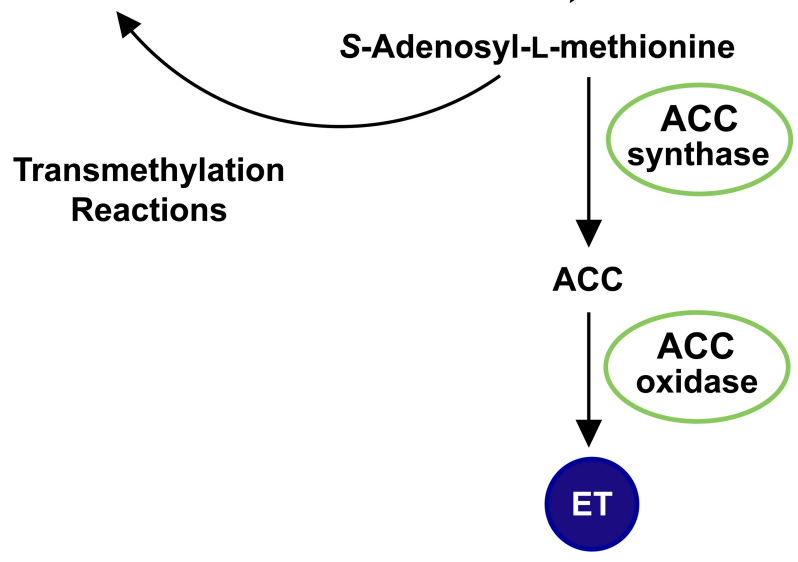

B

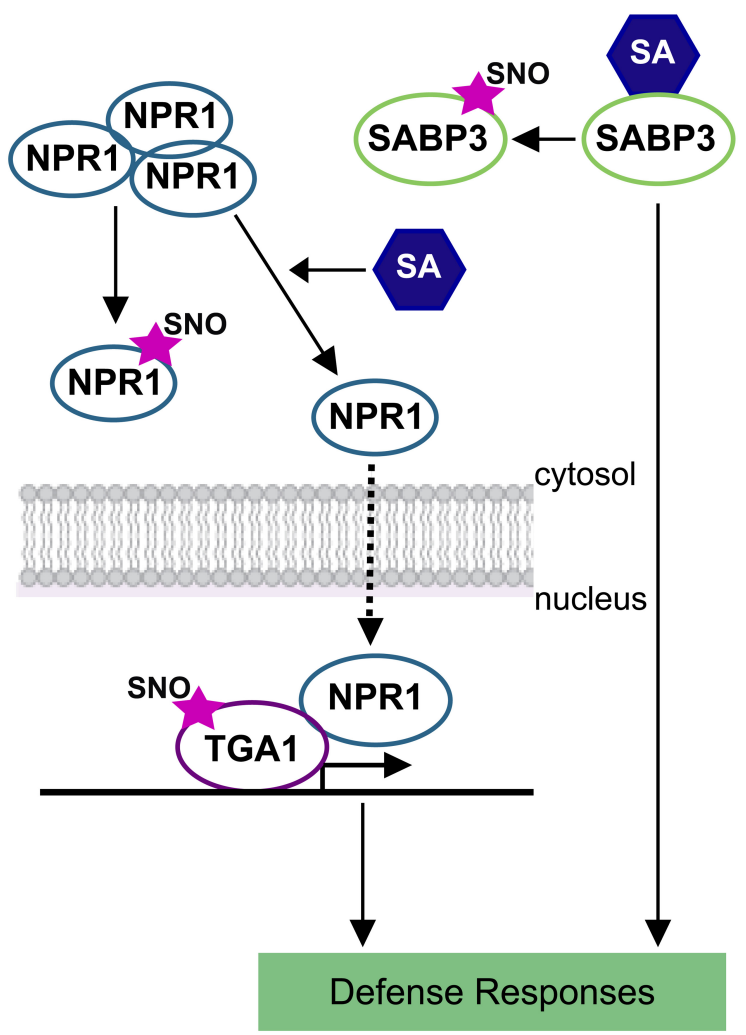

FIGURE 1 | $S$-nitrosylation of target proteins in ethylene biosynthesis and salicylic acid network. The figure shows a schematic representation of methylmethionine cycle in the ethylene (ET) synthesis (A) and salicylic acid (SA) signaling networks (B). Protein $S$-nitrosothiols are represented by an SNO mark. References to physiological processes regulated by hormones, and subcellular localizations in the cell are also indicated. SAHase, adenosylhomocysteinase; MET synthase, cobalamin-independent methionine synthase; MAT, methionine adenosyltransferase; ACC, aminocyclopropane-1carboxylic acid; SABP3, salicylic acid binding protein 3; NPR1, non-expresser of pathogenesis-related gene1 protein; TGA1, transcription factor TGA1. channel at the guard cell plasma membrane or a closely associated regulatory protein through $S$-nitrosylation (Sokolovski and Blatt, 2004). However, the physiological significance of this regulation remains unexplored.

\section{TARGETS FOR PROTEIN S-NITROSYLATION IN SIGNALING PATHWAYS OF GROWTH-PROMOTING PHYTOHORMONES AUXINS AND CYTOKININS}

Auxins and cytokinins (CKs) are critical regulators of cell division, expansion, and differentiation. Relatively recent breakthroughs were found by comparing functions of NO and the well-known growth-promoting hormones (reviewed by Mur etal., 2013). There are several examples of NO and auxin overlapping effects during shoot and root organogenesis such as, NO mediation of auxin-induced adventitious and lateral roots (Pagnussat et al., 2002; Correa-Aragunde et al., 2004), root hair formation (Lombardo et al., 2006), and adventitious root formation (Pagnussat et al., 2003). NO stimulates the activation of cell division and embryogenic cell formation in leaf protoplast in the presence of auxin (Otvos etal., 2005). Copper-induced morphological responses are also mediated by auxin and NO in Arabidopsis seedlings (Peto etal., 2011). All these previous evidences led to investigate the possible interplay between these two signal molecules. Briefly, in the case of auxin, its perception is mediated by the F-box protein TIR1 (transport inhibitor response1) and the related proteins, AUXIN SIGNALING F-BOX proteins (AFBs; Dharmasiri et al., 2005; Kepinski and Leyser, 2005). Auxin binding stabilizes the interaction between TIR1/AFBs and the transcriptional repressor proteins, auxin/indole-3-acetic acid (Aux/IAA) causing a rapid proteasomal degradation of them (Gray et al., 2001). Then, Aux/IAA degradation results in the activation of transcriptional responses with the concomitant impact in plant growth and development (Tan etal., 2007). In an attempt to study the possible mechanism by which $\mathrm{NO}$ might regulate auxin signaling, $S$-nitrosylation of auxin receptor was analyzed. S-nitrosylation of TIR1 was demonstrated by Terrile et al. (2012). This redox-based modification enhances the efficiency by which TIR1 interacts with Aux/IAAs facilitating their degradation and modulating auxin signaling during root growth in Arabidopsis seedlings (Figure 2). Particularly, Cys-140 is a critical residue for TIR1-Aux/IAA interaction and TIR1 function. $S$-nitrosylation of TIR1 represents an efficient mechanism by which NO might enhance sensitivity and/or ligand selectivity. Furthermore, NO modulation of auxin signaling is more complex 
since a combinatorial TIR1/AFB-Aux/IAA co-receptor system could be assembled, contributing to the versatility of auxin response (Calderon Villalobos et al., 2012). However, cellular effectors of denitrosylation remain to be explored. Recently, Correa-Aragunde et al. (2013) described a new convergence where auxins are thought to influence $S$-nitrosylation/denitrosylation balance in Arabidopsis roots. The antioxidant enzyme, APX1 is an $S$-nitrosylation target and auxin induces denitrosylation and partial inhibition of its activity (Correa-Aragunde et al., 2013). These authors postulated that an auxin-regulated balance of APX1 S-nitrosylation/denitrosylation state contributes to a fine-tuned control of reactive oxygen species (ROS) that finally impacts on root architecture and development. Recent studies have pointed out the correlation between ROS and auxin homeostasis in signal transduction during plant development and stress response (Tognetti et al., 2012). In this direction, Bashandy etal. (2010) also highlighted the intercellular redox status as a critical parameter determining plant development through modulation of auxin signaling, transport, and homeostasis. Although our knowledge about auxin and NO is currently being born, most probably $S$-nitrosylation/denitrosylation is of great impact throughout to interlink these two molecules along plant lifecycle.

Plant hormones CKs are well known for their ability to promote cell division and they are associated with growth and development, including lateral root formation and nodulation in legumes (Gonzalez-Rizzo et al., 2006; Murray et al., 2007; Tirichine et al., 2007), circadian rhythms (Salome et al., 2006), and shoot and root development (Werner and Schmulling, 2009). Recently, NO-mediated CK functions have been associated to cell proliferation and meristem maintenance in Arabidopsis (Shen etal., 2013). CKs are perceived and mediated by a multi-step two-component circuit through a histidine and aspartate phosphorelay (Muller and Sheen, 2007). CKs regulate their signals through a variety of mechanisms, such as modulating transcription, controlling phosphorelay and regulating protein localization and stability (To and Kieber, 2008). In a recent report, Feng et al. (2013) demonstrated that NO represses CK signaling by inhibiting the phosphorelay activity through $S$-nitrosylation. Interestingly, the authors showed that NO-overproducing mutants, nox-1 (NO overproducer 1) and gsnor1-3 do not respond to CK-induced shoot regeneration in Arabidopsis explants. Moreover, gsnor1-3 has a substantial reduction on the expression of the primary response regulator genes (ARRs) for CK signaling. Centrally, by the use of an in vivo biotin-switch assay, it was demonstrated that the histidine phosphotransfer protein AHP1 is in planta S-nitrosylated under normal growth conditions. Cys-115 was proposed as an $S$-nitrosylated residue. Comprehensively, AHP1 S-nitrosylation compromises CK action revealing again, a mechanism through which CK signaling components perceive and integrate a redox signal in the regulation of plant growth and development (Figure 2). Although several lines of evidence support the involvement of NO in CK signaling (Carimi et al., 2005; Tun et al., 2008), other works claim an opposite effect of NO in CK action (Werner et al., 2003; Riefler et al., 2006; Xiao-Ping and Xi-Gui, 2006). Much more recently, a direct interaction between $\mathrm{NO}$ and $\mathrm{CK}$ has been also described (Liu et al., 2013). In summary, NO roles could

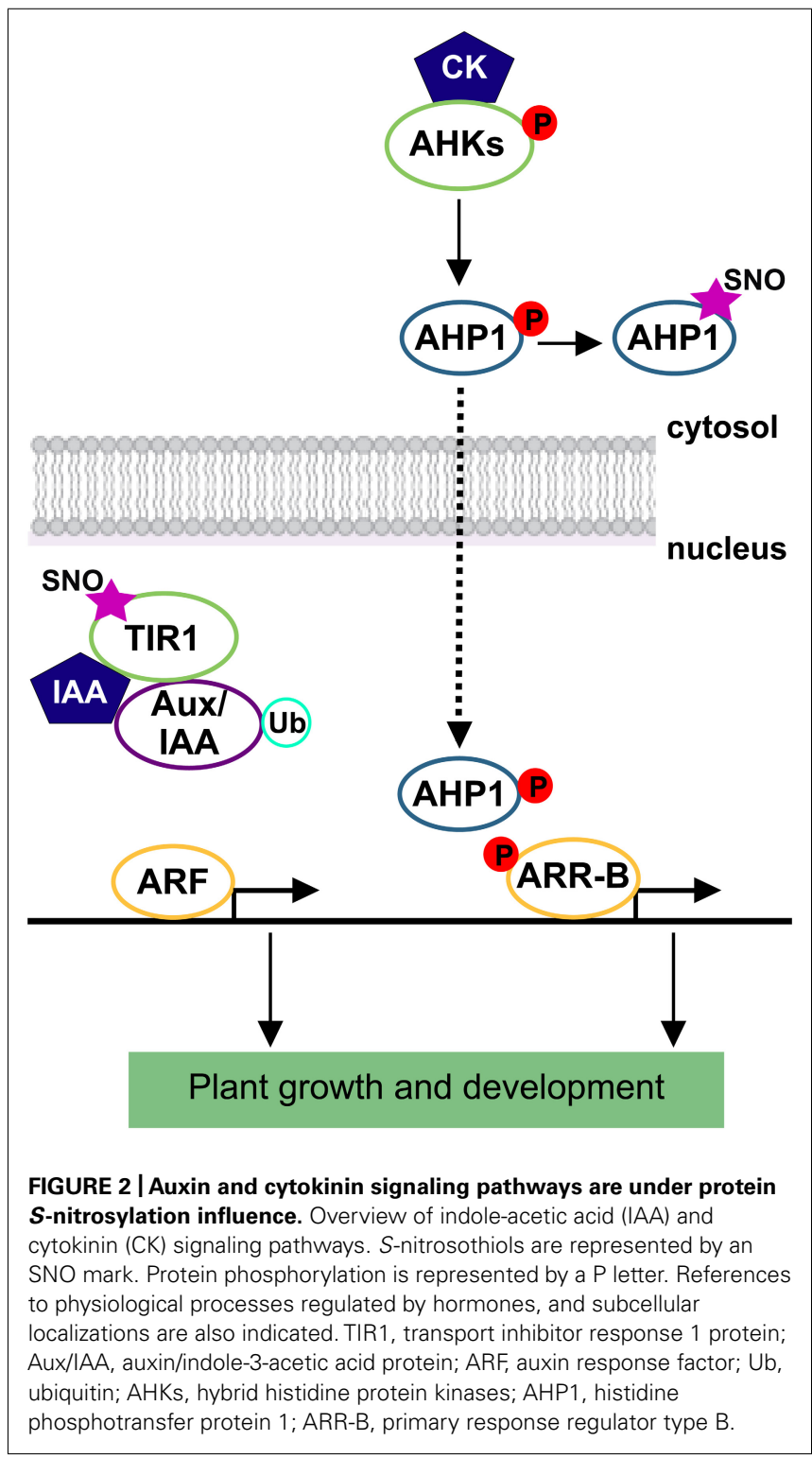

be of the most varied because in addition to its own action it meets specific cellular functions according to the target molecules amending within the routes of hormonal regulation in plant cells.

\section{CONCLUDING REMARKS AND PERSPECTIVES}

$\mathrm{NO}$ is a fascinating molecule with remarkable feats and properties to modulate signaling pathways in biological systems. The bioactivity of NO is high enough for it to occur in a wide variety of biochemical circumstances. S-nitrosylation/denitrosylation is currently accepted as critical redox-mediated regulation processes in plant cells. Certainly, $S$-nitrosylation could be a possible mechanism by which NO impacts on plant hormonal regulation by modulating hormone biosynthesis, perception, transport, and/or degradation. Clearly, multiple layers of interactions may be involved in the plant hormones and NO cross-talks, depending on complex biological and biochemical scenarios in cells. However, 
nowadays fragmented studies on its in vivo function hamper our thorough understanding on hormone-NO cross-talking. Probably, high-throughput genetic and protein-based approaches in combination with a deeper understanding on the basic structure/function relationships of NO generating systems will shed light on this scientific riddle.

\section{REFERENCES}

Abat, J. K., Mattoo, A. K., and Deswal, R. (2008). S-nitrosylated proteins of a medicinal CAM plant Kalanchoe pinnata-ribulose-1,5-bisphosphate carboxylase/oxygenase activity targeted for inhibition. FEBS J. 275, 2862 2872. doi: 10.1111/j.1742-4658.2008. 06425.x

Astier, J., and Lindermayr, C. (2012). Nitric oxide-dependent posttranslational modification in plants: an update. Int. J. Mol. Sci. 13, $15193-$ 15208. doi: 10.3390/ijms131115193

Bashandy, T., Guilleminot, J., Vernoux, T., Caparros-Ruiz, D., Ljung, K., Meyer, Y., et al. (2010). Interplay between the NADP-linked thioredoxin and glutathione systems in Arabidopsis auxin signaling. Plant Cell 22, 376-391. doi: 10.1105/tpc.109. 071225

Benhar, M., Forrester, M. T., and Stamler, J. S. (2009). Protein denitrosylation: enzymatic mechanisms and cellular functions. Nat. Rev Mol. Cell Biol. 10, 721-732. doi: $10.1038 / \mathrm{nrm} 2764$

Calderon Villalobos, L. I., Lee, S., De Oliveira, C., Ivetac, A., Brandt, W., Armitage, L., et al. (2012). A combinatorial TIR1/AFB-Aux/IAA co-receptor system for differential sensing of auxin. Nat. Chem. Biol. 8, 477-485. doi: 10.1038/nchembio.926

Carimi, F., Zottini, M., Costa, A., Cattelan, I., De Michele, R., Terzi, M., et al. (2005). NO signalling in cytokinin-induced programmed cell death. Plant Cell Environ. 28, 11711178. doi: 10.1111/j.1365-3040.2005. 01355.x

Correa-Aragunde, N., Foresi, N., Delledonne, M., and Lamattina, L. (2013). Auxin induces redox regulation of ascorbate peroxidase activity by $S$ nitrosylation/denitrosylation balance resulting in changes of root growth pattern in Arabidopsis. J. Exp. Bot. doi: $10.1093 / \mathrm{jxb} / \mathrm{ert} 172$

Correa-Aragunde, N., Graziano, M., and Lamattina, L. (2004). Nitric oxide plays a central role in determining lateral root development in tomato. Planta 218, 900-905. doi: 10.1007/s00425-0031172-7

Dharmasiri, N., Dharmasiri, S., and Estelle, M. (2005). The F-box protein TIR1 is an auxin receptor.
Nature 435, 441-445. doi: 10.1038/ nature 03543

Fan, L. M., Zhao, Z., and Assmann, S. M. (2004). Guard cells: a dynamic signaling model. Curr. Opin. Plant Biol. 7, 537-546. doi: 10.1016/j.pbi.2004.07.009

Feechan, A., Kwon, E., Yun, B. W., Wang, Y., Pallas, J. A., and Loake, G. J. (2005). A central role for $S$-nitrosothiols in plant disease resistance. Proc. Natl. Acad. Sci. U.S.A. 102, 8054-8059. doi: 10.1073/pnas.0501456102

Feng, J., Wang, C., Chen, Q., Chen, H., Ren, B., Li, X., et al. (2013). $S$-nitrosylation of phosphotransfer proteins represses cytokinin signaling. Nat. Commun. 4, 1529. doi: $10.1038 /$ ncomms 2541

Fujita, M., Fujita, Y., Noutoshi, Y., Takahashi, F., Narusaka, Y., Yamaguchi-Shinozaki, K., et al. (2006). Crosstalk between abiotic and biotic stress responses: a current view from the points of convergence in the stress signaling networks. Curr. Opin. Plant Biol. 9, 436-442. doi: 10.1016/j.pbi.2006. 05.014

Gonzalez-Rizzo, S., Crespi, M., and Frugier, F. (2006). The Medicago truncatula CRE1 cytokinin receptor regulates lateral root development and early symbiotic interaction with Sinorhizobium meliloti. Plant Cell 043778

Gray, W. M., Kepinski, S., Rouse, D., Leyser, O., and Estelle, M. (2001). Auxin regulates SCF(TIR1)dependent degradation of AUX/IAA proteins. Nature 414, 271-276. doi: 10.1038/35104500 O., Marshall, H. E., and Stamler, J. S. (2005). Protein S-nitrosylation: purview and parameters. Nat. Rev. Mol. Cell Biol. 6, 150-166. doi: 10.1038/nrm1569

Kepinski, S., and Leyser, O. (2005). The Arabidopsis F-box protein TIR1 is an auxin receptor. Nature 435, 446-451. doi: 10.1038/nature03542

Lamattina, L., and Polacco, J. C. (2007). Nitric Oxide in Plant Growth, Development and Stress Physiology. Berlin: Springer-Verlag. doi: 10.1007/11563280

Lindermayr, C., Saalbach, G., Bahnweg, G., and Durner, J. (2006). 18, 2680-2693. doi: 10.1105/tpc.106.

Hess, D. T., Matsumoto, A., Kim, S.

\section{ACKNOWLEDGMENTS}

Ramiro París, María C. Terrile, and Claudia A. Casalongué are researchers from CONICET. María J. Iglesias is postgraduate fellow from the same Institution. Work in the lab of Claudia A. Casalongué is supported by grants from CONICET, ANPCyT, and Universidad Nacional de Mar del Plata.

Differential inhibition of Arabidopsis methionine adenosyltransferases by protein S-nitrosylation. J. Biol. Chem. 281, 4285-4291. doi: 10.1074/jbc M511635200

Lindermayr, C., Saalbach, G., and Durner, J. (2005). Proteomic identification of $S$-nitrosylated proteins in Arabidopsis. Plant Physiol. 137, 921-930. doi: 10.1104/pp.104. 058719

Lindermayr, C., Sell, S., Muller, B., Leister, D., and Durner, J. (2010). Redox regulation of the NPR1-TGA1 system of Arabidopsis thaliana by nitric oxide. Plant Cell 22, 2894-2907. doi: 10.1105/tpc.109. 066464

Liu, W. Z., Kong, D. D., Gu, X. X. Gao, H. B., Wang, J. Z., Xia, M., et al. (2013). Cytokinins can act as suppressors of nitric oxide in Arabidopsis. Proc. Natl. Acad. Sci. U.S.A. 110, 1548-1553. doi: 10.1073/pnas. 1213235110

Loake, G., and Grant, M. (2007). Salicylic acid in plant defence the players and protagonists. Curr. Opin. Plant Biol. 10, 466-472. doi: 10.1016/j.pbi.2007.08.008

Lombardo, M. C., Graziano, M., Polacco, J., and Lamattina, L. (2006). Nitric oxide functions as a positive regulator of root hair development. Plant Signal. Behav. 1, 28-33. doi: 10.4161/psb.1.1.2398

Malik, S. I., Hussain, A., Yun, B. W., Spoel, S. H., and Loake, G. J. (2011). GSNOR-mediated de-nitrosylation in the plant defence response. Plant Sci. 181, 540-544. doi: 10.1016/j. plantsci.2011.04.004

Martinez-Ruiz, A., Araujo, I. M., Izquierdo-Alvarez, A., HernansanzAgustin, P., Lamas, S., and Serrador, J. M. (2013). Specificity in $S$-nitrosylation: a short-range mechanism for NO signaling? Antioxid. Redox Signal. doi: 10.1089/ars.2012.5066 [Epub ahead of print].

Martinez-Ruiz, A., and Lamas, S. (2007). Signalling by NO-induced protein $S$-nitrosylation and $S$ glutathionylation: convergences and divergences. Cardiovasc. Res. 75, 220 228. doi: 10.1016/j.cardiores.2007. 03.016

Muller, B., and Sheen, J. (2007). Arabidopsis cytokinin signaling pathway. Sci. STKE 2007, cm5. doi: $10.1126 /$ stke. $4072007 \mathrm{~cm} 5$

Mur, L. A., Mandon, J., Persijn, S., Cristescu, S. M., Moshkov, I. E., Novikova, G. V., et al. (2013). Nitric oxide in plants: an assessment of the current state of knowledge. $A o B$ Plants 5, pls052. doi: 10.1093/aobpla/pls052

Murray, J. D., Karas, B. J., Sato, S., Tabata, S., Amyot, L., and Szczyglowski, K. (2007). A cytokinin perception mutant colonized by Rhizobium in the absence of nodule organogenesis. Science 315, 101-104. doi: 10.1126/science. 1132514

Otvos, K., Pasternak, T. P., Miskolczi, P., Domoki, M., Dorjgotov, D., Szucs, A., et al. (2005). Nitric oxide is required for, and promotes auxin-mediated activation of, cell division and embryogenic cell formation but does not influence cell cycle progression in alfalfa cell cultures. Plant J. 43, 849860. doi: 10.1111/j.1365-313X.2005. 02494.x

Pagnussat, G. C., Lanteri, M. L., and Lamattina, L. (2003). Nitric oxide and cyclic GMP are messengers in the indole acetic acid-induced adventitious rooting process. Plant Physiol. 132, 1241-1248. doi: 10.1104/pp.103. 022228

Pagnussat, G. C., Simontacchi, M., Puntarulo, S., and Lamattina, L. (2002). Nitric oxide is required for root organogenesis. Plant Physiol. 129, 954-956. doi: 10.1104/pp. 004036

Peto, A., Lehotai, N., Lozano-Juste, J., Leon, J., Tari, I., Erdei, L., et al. (2011). Involvement of nitric oxide and auxin in signal transduction of copper-induced morphological responses in Arabidopsis seedlings. Ann. Bot. 108, 449-457. doi: 10.1093/aob/mcr176

Riefler, M., Novak, O., Strnad, M., and Schmulling, T. (2006). Arabidopsis cytokinin receptor mutants reveal functions in shoot growth, leaf senescence, seed size, germination, root development, and cytokinin metabolism. Plant Cell 18, 40-54. doi: 10.1105/tpc.105.037796

Salome, P. A., To, J. P., Kieber, J. J., and McClung, C. R. (2006). Arabidopsis response regulators ARR3 and ARR4 play cytokinin-independent roles in 
the control of circadian period. Plant Cell 18, 55-69. doi: 10.1105/tpc.105. 037994

Shen, Q., Wang, Y. T., Tian, H., and Guo, F. Q. (2013). Nitric oxide mediates cytokinin functions in cell proliferation and meristem maintenance in Arabidopsis. Mol. Plant. doi: 10.1093/mp/sss148 [Epub ahead of print]

Simontacchi, M., Garcia-Mata, C., Bartoli, C. G., Santa-Maria, G. E., and Lamattina, L. (2013). Nitric oxide as a key component in hormone-regulated processes. Plant Cell Rep. 32, 853-866. doi: 10.1007/ s00299-013-1434-1

Sokolovski, S., and Blatt, M. R. (2004). Nitric oxide block of outwardrectifying $\mathrm{K}+$ channels indicates direct control by protein nitrosylation in guard cells. Plant Physiol. 136, 4275-4284. doi: 10.1104/pp.104. 050344

Spoel, S. H., Koornneef, A., Claessens S. M. C., Korzelius, J. P., Van Pelt, J. A., Mueller, M. J., et al. (2003). NPR1 Modulates cross-talk between salicylate- and jasmonatedependent defense pathways through a novel function in the cytosol. Plant Cell 15, 760-770. doi: 10.1105/tpc. 009159

Stamler, J. S., Lamas, S., and Fang, F. C. (2001). Nitrosylation. the prototypic redox-based signaling mechanism. Cell 106, 675683. doi: 10.1016/S0092-8674(01) 00495-0
Tada, Y., Spoel, S. H., PajerowskaMukhtar, K., Mou, Z., Song, J., Wang, C., etal. (2008). Plant immunity requires conformational charges of NPR1 via $S$-nitrosylation and thioredoxins. Science 321, 952-956. doi: 10.1126/science. 1156970

Tan, X., Calderon-Villalobos, L. I., Sharon, M., Zheng, C., Robinson, C. V., Estelle, M., et al. (2007). Mechanism of auxin perception by the TIR1 ubiquitin ligase. Nature 446, 640-645. doi: 10.1038/ nature 05731

Terrile, M. C., Paris, R., CalderonVillalobos, L. I., Iglesias, M. J., Lamattina, L., Estelle, M. etal. (2012). Nitric oxide influences auxin signaling through $S$-nitrosylation of the Arabidopsis TRANSPORT INHIBITOR RESPONSE 1 auxin receptor. Plant J. 70, 492-500. doi: 10.1111/j.1365313X.2011.04885.

Tirichine, L., Sandal, N., Madsen, L. H., Radutoiu, S., Albrektsen, A. S., Sato, S., et al. (2007). A gain-of-function mutation in a cytokinin receptor triggers spontaneous root nodule organogenesis. Science 315, 104-107. doi: 10.1126/ science. 1132397

To, J. P., and Kieber, J. J. (2008). Cytokinin signaling: twocomponents and more. Trends Plant Sci. 13, 85-92. doi: 10.1016/j.tplants. 2007.11.005

Tognetti, V. B., Muhlenbock, P. and Van Breusegem, F. (2012).
Stress homeostasis - the redox and auxin perspective. Plant Cell Environ. 35, 321-333. doi: 10.1111/j.1365 3040.2011.02324.x

Tun, N. N., Livaja, M., Kieber, J. J., and Scherer, G. F. (2008). Zeatin-induced nitric oxide (NO) biosynthesis in Arabidopsis thaliana mutants of $\mathrm{NO}$ biosynthesis and of two-component signaling genes. New Phytol. 178, 515-531. doi: 10.1111/j.1469-8137. 2008.02383.x

Vlot, A. C., Dempsey, D. A., and Klessig, D. F. (2009). Salicylic acid, a multifaceted hormone to combat disease. Annu. Rev. Phytopathol. 47, 177-206. doi: 10.1146/annurev.phyto.050908. 135202

Wang, Y. Q., Feechan, A., Yun, B. W., Shafiei, R., Hofmann, A., Taylor, P., et al. (2009). S-nitrosylation of AtSABP3 antagonizes the expression of plant immunity. J. Biol. Chem 284, 2131-2137. doi: $10.1074 / \mathrm{jbc}$ M806782200

Werner, T., Motyka, V., Laucou, V., Smets, R., Van Onckelen, H., and Schmulling, T. (2003). Cytokinin-deficient transgenic Arabidopsis plants show multiple developmental alterations indicating opposite functions of cytokinins in the regulation of shoot and root meristem activity. Plant Cell 15, 2532-2550. doi: 10.1105/ tpc.014928

Werner, T., and Schmulling, T. (2009). Cytokinin action in plant development. Curr. Opin. Plant
Biol. 12, 527-538. doi: 10.1016/j. pbi.2009.07.002

Xiao-Ping, S., and Xi-Gui, S. (2006) Cytokinin- and auxin-induced stomatal opening is related to the change of nitric oxide levels in guard cells in broad bean. Physiol. Plant. 128, 569-579. doi: 10.1111/j.13993054.2006.00782.x

Conflict of Interest Statement: The authors declare that the research was conducted in the absence of any commercial or financial relationships that could be construed as a potential conflict of interest.

Received: 30 April 2013; accepted: 15 July 2013; published online: 01 August 2013. Citation: París R, Iglesias MJ, Terrile MC and Casalongué CA (2013) Functions of S-nitrosylation in plant hormone networks. Front. Plant Sci. 4:294. doi: 10.3389/fpls.2013.00294

This article was submitted to Frontiers in Plant Physiology, a specialty of Frontiers in Plant Science.

Copyright: (c) 2013 París, Iglesias, Terrile and Casalongué. This is an open-access article distributed under the terms of the Creative Commons Attribution License (CC BY). The use, distribution or reproduction in other forums is permitted, provided the original author(s) or licensor are credited and that the original publication in this journal is cited, in accordance with accepted academic practice. No use, distribution or reproduction is permitted which does not comply with these terms. 